\title{
Cinema e educação: o velho, o novo e outros territórios na formação docente
}

\author{
Cine y educacion: the old, the new and other territories in teacher training
}

Fernanda Omelczuk Walter ${ }^{1}$

\section{Resumo}

O trabalho compartilha reflexões de uma pesquisa de iniciação científica sobre experiências de cinema realizadas por professores em formação com o público de uma instituição de longa permanência para idosos em São João del-Rei/MG. Desenvolvemos três recortes de análises: o contraste rítmico-produtivo da relação professor-criança-velho; o encontro dos alunos com a velhice como experiência de estranheza e acolhimento, já que tradicionalmente o encontro é com a criança; e o lugar da imaginação em diferentes fases da vida. Observamos que a formação de professores no espaço asilar, intensificada pelo cinema como experiência estética, desloca o fazer docente, o cinema e a experiência do velho - entendendo o termo velho como tudo aquilo que envelhece, pessoas, objetos, tempos, ideias, memórias, e/ou tudo aquilo que vive - em meio aos discursos contemporâneos de inovação pedagógica.

Palavras-chave: cinema e educação; formação docente; educação e terceira idade.

\begin{abstract}
The work shares the reflections of a scientific initiation research about cinema experiences achieved by teachers in formation with the public of a long-term care institution for the elderly in São João del-Rei / MG. We developed three analysis clippings: the rhythmic-productive contrast of the teacher-child-old relationship; the meeting of students with old age as an experience of strangeness and welcome, since traditionally the meeting is with the child; and the place of imagination at different stages of life. We note that teacher education in the asylum space, intensified by cinema as an aesthetic experience, displaces teaching, cinema and the experience of the old - understanding the term old as everything that grows old, people, objects, times, ideas, memories, and / or everything that lives - in the midst of contemporary discourses of pedagogical innovation.
\end{abstract}

Key-words: cinema and education; teacher training; education and third age.

\section{Chegando em um (outro) território}

\footnotetext{
${ }^{1}$ Doutora em Educação pela Universidade Federal do Rio de Janeiro (UFRJ). Professora Adjunta do Departamento de Ciências da Educação - DECED - da Universidade Federal de São João del Rei (UFSJ). Email: fernandaow@ufsj.edu.br
} 
A educação se multiplica em diferentes momentos da vida social e não se restringe aos espaços escolares. As instituições educativas formais, entretanto, são os principais espaços de atuação do professor, sendo sua formação direcionada para a experiência nesse território particular, que possui modos de operar específicos. Uma dessas operações consiste em chamar a atenção para matérias do mundo. O professor apresenta para a nova geração coisas com as quais o aluno possa construir interesse e se envolver (MASSCHELEIN; SIMONS, 2014).

Esse gesto se fundamenta, dentre outros, na diferença do tempo de vida, experiências de vida, de quem apresenta algo - o professor - a quem chega para viver essa experiência - o aluno. Quando um docente em formação entra numa Instituição de Longa Permanência para Idosos ILPI -, suspendemos - ou invertemos - essa distância temporal. Que devires outros de ser mestre são colocados em movimento nesse encontro atravessado e intensificado pela experiência do cinema? Quais desterritorializações atravessam a escola, os alunos, os idosos que vivem nestas instituições, e o cinema com esse encontro? Por que promover experiências de formação para futuros professores, nesses espaços, com o cinema?

Começamos falando em idosos para personificar o público, que de acordo com a Organização Mundial de Saúde (OMS) tem 60 anos ou mais, porém, nos interessa neste trabalho pensar os desdobramentos da referência à esta fase da vida como sendo composta de pessoas velhas. Entendemos que o termo velho, por ser mais abrangente e ambíguo que a palavra idoso, nos permite referi-lo a tudo aquilo que envelhece, e ao modo como somos afetados pelo que envelhece em contraste ao que é novo. Pessoas, plantas, objetos, tempos, ideias, memórias envelhecem, como condição do que está vivo.

Se vivemos, por um lado, um intenso processo de envelhecimento, por outro, valorizamos, cada vez mais, a juventude e a inovação. Na educação, inovar tem sido uma palavra de ordem. Tudo parece velho e atrasado na escola: seu formato, seus dispositivos, suas metodologias. Nesse contexto, Fresquet (2013) pensa o cinema como uma alternativa a insuflar vida e fertilidade à "velha e ressecada educação", apostando que o cinema traz para o ambiente austero da pedagogia dimensões humanas, que costumam ser excluídas do fazer científico: um mistério, a invenção, o sonho.

Mas, e o cinema, é velho ou novo? E o que seria ser velho ou ser novo? A que novo aspiramos? Interessa-nos tencionar estas questões: sair da escola para o asilo, ensaiar fazer escola, iniciar a docência e o cinema em territórios outros, num encontro intergeracional 
embaralhado, invertendo fluxos, confundindo, quem sabe, quem aprende, quem ensina, "para esclarecer", como canta Tom Zé. O cinema é nosso elo comum, o elemento sobre o qual partimos, a matéria que escolhemos.
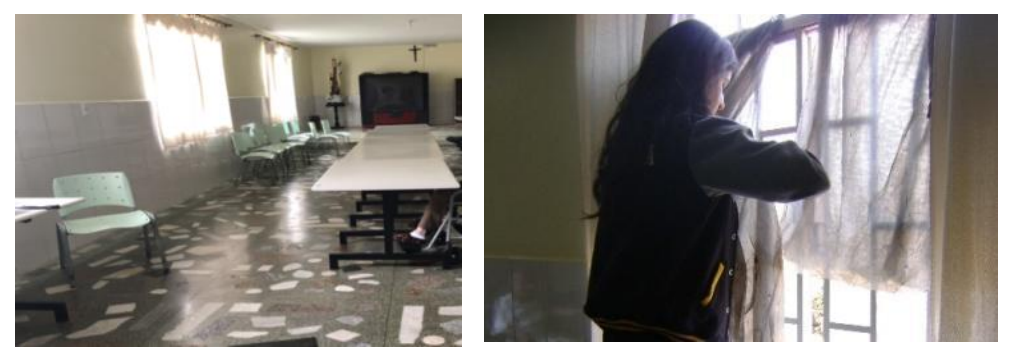

A ideia não é distrair os idosos, para que se esqueçam do que estão vivendo, até por que entendemos que as velhices são muitas. O cinema, porque arte, recebe a aventura humana com intensidade e acolhe tudo como parte de nossas potências de vida, experimentações pré-simbólicas abertas a múltiplos sentidos. Queremos viver juntos uma travessia com a imagem, onde cada um possa compartilhar o que vê, sente e cria. Nisso, reside uma potência da experiência estética, como lugar de afirmação da igualdade de alunos, idosos e crianças, e o exercício de invenção (DUARTE JÚNIOR, 1988; RANCIÈRE, 2011).

É a partir dessas questões que compartilharemos, neste trabalho, alguns resultados de um projeto ${ }^{2}$, que, entre $2017 \mathrm{e}$

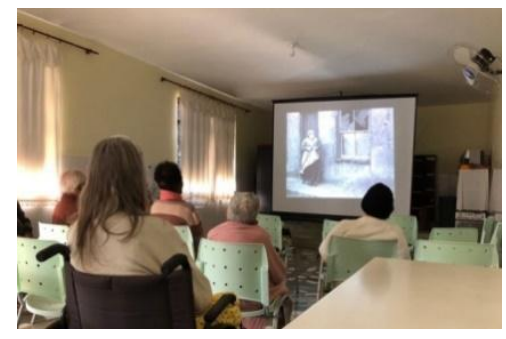
2018, promoveu experiências de cinema junto ao público de uma $\operatorname{ILPI}^{3}$ na cidade de São João

del-Rei/MG. Em sessões semanais, câmeras, projetores, sacolas pretas para cobrir as janelas, caixas de som e o telão adentravam a instituição, para trazer filmes, conversas e experiências com o cinema, que convidavam o idoso a traçar novos caminhos por aquele território.

\footnotetext{
${ }^{2}$ Tratou-se do projeto de iniciação científica: "Experiências sensíveis com a sétima arte, outros cinemas, outros territórios: outras formas de formar?" (aprovado no Edital PROPE/UFSJ/003-2017). Especial agradecimento ao trabalho da aluna bolsista Jacqueline de Castro Martins Ferreira Silveira que participou da pesquisa e da geração dos dados a partir dos quais este texto foi desenvolvido.

${ }^{3}$ A Instituição onde foi realizado o trabalho autorizou a pesquisa após análise do projeto e assinatura do Termo de Consentimento Livre e Esclarecido e forneceu também Autorização de Imagem. Ambos foram anexados junto ao relatório final de Iniciação Científica.
} 
Quando chegamos com o cinema - lugar da "indisciplina", do imprevisível e do indefinido como o é toda arte -, sentimos que uma "desordem" física e subjetiva emerge de tal forma que se configura como uma "parada" em desafios iniciais para a realização do trabalho com a sétima arte. Imaginamos que não é apenas o excesso de luz que é filtrado pelo plástico preto, não é só a televisão que dá lugar à projeção colorida ou preta e branca, não é só um registro cinematográfico que é feito naquele espaço, não é só uma parede branca que ganha texturas, contornos, profundidade, cores. A repetição semanal desses gestos cria um ritmo para nossa chegada e a do cinema e cria, também, expectativa nos moradores, instaurando um outro ritmo no ambiente físico e subjetivo (FERREIRA; OMELCZUK, 2018).

Mas o albergue não é só um lugar material demarcado pelas paredes, janelas, poltronas, televisão e móveis, que regulamentam a rotina da vida comum. Lugares são, também, redes de relações, lugares de encontro, adornados por dispositivos de afetos, comportamentos, subjetividades, sempre provisórios.

A ambientação necessária para que o cinema possa acontecer nesse lugar cria um outro lugar. Inventamos um ambiente-cinema numa sala de estar asilar. Criamos uma prática (pedagógica, de espectador, de cinema), transformando-o em outra coisa. Pensando com Deleuze e Guattari (2012, p. 129) que "o fator territorializante deve ser buscado no devir-expressivo do ritmo ou da melodia, na emergência de qualidades próprias (cor, odor, som, silhueta)", suspeitamos que o cinema no albergue, enquanto experiência estética, reconfigura a cena, desloca e abre processos subjetivos ainda não codificados; desterritorializa o cinema, os moradores, nós mesmos.

As observações e registros desenhados no diário de campo são um exercício de criação. Criamos notas, traços, ideias, sensações, imagens e relações, e recriamos aquele território e nosso território docente, compondo um território comum com os idosos e demais presentes. Ao escrevermos, inspiramos teoria, tecemos pensamento - vida. E melhor, percebemos a potência disso na contribuição da produção de conhecimento coletivo. Inspiramo-nos na cartografia como perspectiva metodológica, uma vez que "cartografia como prática de pesquisa é o traçado desse plano da experiência, se faz presente nos avanços e nas paradas, em campo, em letras e linhas, na escrita, em nós" (KASTRUP, 2014, p. 73).

Para pensar, analisar e escrever sobre os encontros com os idosos, com o cinema, com a criação, desenvolvemos uma postura cartográfica. A cartografia parte do reconhecimento de que estamos em processos - como o são afinal a subjetividade humana, a aprendizagem, o 
envelhecimento e a vida, os encontros e os imprevisíveis que se abrem na experiência com as imagens, com as histórias, com a memória, com exercícios de criação.

Por atender à emergência de um processo de construção de subjetividade que se dá na relação entre o que outrora era chamado sujeito-objeto, a cartografia tem se mostrado uma prática de pesquisa cada vez mais presente em estudos do campo das ciências humanas. Isso porque na cartografia - em nosso caso corporificada no gesto de narrar, descrever, acompanhar sensível e com olhar teórico o território existencial que emerge do encontro com o cinema e com os idosos - temos como pressuposto epistemológico que toda pesquisa é intervenção. Não há sujeitos de pesquisa objetáveis, somos todos pessoas em relação, afetando e sendo afetados, criando realidade, criando dados.

Desse modo, a cartografia nos implica em uma parceria ética epistemológica na construção de mundo e de conhecimento. Os idosos com quem convivemos durante quase um ano de pesquisa foram, portanto, Francisco, Lourdes, Helena, Erondina, e tantas outras pessoas reais. Sujeitos atuantes, protagonistas e não objetos de uma pesquisa. Assumimos o compromisso ${ }^{4}$ de não alterar o nome dos participantes que são conosco criadores dos dados na medida em que seus movimentos, suas falas e criações compõe a cartografia que aqui desenhamos.

Nas linhas a seguir, desenvolveremos três recortes de olhares sobre essa experiência: o contraste rítmico-produtivo da relação professor-criança-velho; o encontro com a velhice como experiência de estranheza e acolhimento; e a problematização do lugar da imaginação na construção do conhecimento em diferentes fases da vida.

\section{Compondo e cartografando ritmos de um território: da mão que puxa à mão que retém}

O salão onde realizamos a exibição é um espaço bem iluminado aos fundos da arquitetura do prédio. O caminho até ele é um corredor extenso, que passa por duas antessalas de televisão com sofás e onde algumas idosas costumam ficar. Esse corredor abre ainda passagens para a ala dos homens e para diversas salas administrativas e atravessa o pátio aberto. No salão, há várias mesas e cadeiras utilizadas para diferentes atividades, como bingo, recepção de visitantes e festividades variadas.

\footnotetext{
${ }^{4}$ No que se refere a autorização das imagens, procuramos manter a discrição de rostos e detalhes pessoais, resguardando suas intimidades.
}

Revista Devir Educação, Lavras, vol.3, n.2, p.156-171 jul./dez., 2019. 
O percurso até o salão não é fácil. Decidir ir ao cinema requer dos idosos um grande esforço físico. Quase todos necessitam de ajuda para o deslocamento, seja empurrando-os em suas cadeiras de rodas ou amparando-os a passos curtos e lentos. Ao darmos o braço para um idoso, compomos com ele um ritmo muito diferente ao qual estamos acostumados, especialmente se pensamos no trabalho com crianças pequenas e nas demandas de produção e velocidade da vida escolar, campo privilegiado de atuação do pedagogo.

Chama atenção, portanto, a disponibilidade com que os idosos saem de uma posição confortável, para traçarem um movimento desconhecido e penoso, sem garantias do que vão presenciar. Ao propormos aos idosos realizarem um primeiro exercício de criação, por exemplo, uma senhora, que caminhava muito devagar com sua bengala e sempre com auxílio de um cuidador, pediu para filmar no pátio de entrada do albergue, onde queria registrar a "liberdade".

Nesse caso, o cinema, como imagem, que, para existir, se faz no encontro com a realidade, exigiu e "permitiu" que ela se deslocasse para fora do prédio, o que, raramente, pode fazê-lo na rotina institucional. Para tanto, Lourdes precisou caminhar pelo extenso corredor, que sai do salão até a portaria do albergue, colocando-nos em uma composição rítmica fora dos padrões a que estamos acostumados. Tornamo-nos íntimos de seus passos e ritmos. Quase vinte minutos de trajeto desde o salão até o pátio para filmar um minuto 5 de "liberdade".

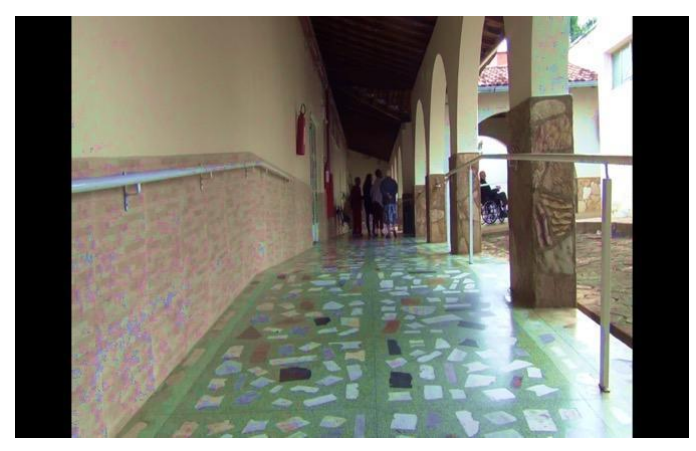

Que território é esse que percorremos? O que seu enquadramento nos permite ver? Segundo Tótora (2013), a velhice vem sendo "reinventada" pelo mercado e pelo consumo via

5 Tratava-se do dispositivo Minutos Lumière, exercício iniciático de criação cinematográfica realizado em diferentes projetos de cinema-educação no Brasil. Mais informações em: cinead.org e http://www.inventarcomadiferenca.org/wp-content/uploads/2017/05/Cadernos_do_Inventar_com_Diferenca.pdf 
atividades físicas e culturais diversas, alimentação, turismo etc., tudo direcionado aos idosos e à manutenção de uma juventude e vitalidade perdidas... Em sua análise, há territórios pelos quais o velho não é aceito em sua singularidade e modo único de expressão, especialmente quando se trata da perda da razão e da produtividade, bases da modernidade - bases também da educação.

Pensamos que, nesse ritmo outro que experimentamos no albergue, há uma potência de não produção, de não fazer, que se aproxima do que Masschelein e Simons (2014) apontam ao falarem do skholar, termo grego que designava um tempo para o presente, tempo livre não para a produção de demandas externas ao estar junto. Originalmente, a escola (skholé) grega era um lugar onde se experimentava esse tempo para a criação livre, para estudar, para aprender, para a própria experiência do presente e do encontro. Nesse aspecto, em relação ao tempo, todos eram iguais dentro da escola, com a mesma oportunidade de fruição temporal e estética - na experiência de ser um aprendiz.

Bárcena (2015) nos ajuda a ampliar essa questão da produtividade temporal ao discutir o modo como marginalizamos as pessoas "descapacitadas" e "improdutivas" do ponto de vista da modernidade - aquelas que, historicamente, são excluídas de participação política por serem acometidas de uma postura não racional, incapazes de cuidarem de si (crianças, loucos, autistas); em nosso caso, incluímos os idosos em situação de institucionalização. Em contrapartida, o autor ressalta que o que nós, humanos, compartimos não é nosso poder de fazer, mas nossa mútua fragilidade e dependência, nossa impotência.

Essa impotência é potente, porque afirma a possibilidade de "negarmos" a produção, de não responder ao que nos é imposto pela modernidade. Trata-se de um gesto, portanto, que celebra a condição humana aberta às múltiplas possibilidades do que podemos nos tornar, ao invés de nos adaptar às subjetividades pré-fabricadas, sejam elas a de um modo único (e sempre ativo) de ser velho, de ser criança, de pensar, conhecer, aprender.

Nesse sentido, o que vivenciamos com as experiências de cinema e os idosos institucionalizados é uma experiência de fazer "escola" - no sentido grego da palavra skholé dentro do asilo. Eles nos freiam a experimentar outro tempo diferente daquele que ficou do lado de fora e afirmam uma singular existência para além das demandas de vida ativa, que, muitas vezes, a terceira idade é incitada a estar.

Assim, a experiência junto aos idosos e ao seu outro tempo, ritmo e (ir)racionalidades contrasta com as demandas da escola produtiva e da criança ativa, cenários mais familiares ao 
docente. Imaginamos que esses encontros possam contribuir para que retornemos à escola mais sensíveis aos modelos de subjetividade, que se impõem na educação, quando o tempo é tão somente o tempo da instituição, pensado sob a lógica cronológica: tempo sucessivo, tempo que disciplina corpos e causas, que tem a capacidade de fazer do conhecimento dimensão relativa apenas da razão.

Já que o fator territorializante se expressa em estéticas de ritmo e percepções, com as experiências de cinema, começamos a nos aproximar dos idosos num cultivo de contato e escuta, que pode abrir para singularidades. $\mathrm{O}$ idoso freia o ritmo acelerado da vida moderna, interrompendo-nos a ver, a ouvir, a acolher o outro e a pensar sobre modos outros de vida.

\section{A velhice - território de estranhezas}

Por que sua pele é tão trincadinha?

(Bartolomeu Campos de Queiroz)

Para Bárcena (2015), o contato com o "estranho" é inquietante, porque, nele, encontramos uma forma genuína de desapropriação, de estranhamento (o fora, o não familiar). O encontro com o estranho rompe com as formas de relação instituídas, trazendo enigmas. A diferença fere; por isso, nós a negamos, evitando a desterritorialização, que pode nos provocar.

Quando pensamos o trabalho de professores em formação com os idosos, almejamos essa experiência pelo desafio que ela provoca no exercício de nos tornarmos íntimos da diferença, de estarmos dentro dela e de abrirmos a possibilidade da hospitalidade, porque o estranho, também, traz, em sua ambivalência, essa potência de hospitalidade, que é a "substituição do medo frente ao estrangeiro pela alegria em seu acolhimento", como define Gallo (2015, p. 5) inspirado em René Schérer. Nessa perspectiva, o outro, um outrem, é um fora, que vibra e abre mundos possíveis em nós, colocando em jogo outra experiência de sentir, memorar, imaginar e pensar; que desestabiliza eixos e provoca rachaduras no eu instituído, diz Orlandi (2014).

Quando isso acontece, vivemos um encontro intensivo, onde o outro não é motivo de fuga ou medo, mas condição para o próprio encontro e hospitalidade. "O sentir e pensar são afetados por conexões diferenciais que se lhes impõem de fora, justamente como acontece nesse conceito de outrem como abertura de mundos possíveis" (ORLANDI, 2014, p. 7). 
Pensamos que o encontro dos futuros professores com velhos, em meio ao discurso de modernidade, pode ser uma experiência de estranheza e hospitalidade: o arrastar dos passos, a voz baixa e rouca, que quase não sai, as falas, pensamentos e narrativas confusas, a pele enrugada, "trincadinha" como diz Bartolomeu Campos de Queiroz. O velho perturba, gera assombro e pânico, algumas vezes vontade de eliminação, isolamento, maus-tratos, inclusive. "Ela [a velhice] é tão inconcebível que se fabrica uma cadeia de 'micro-gulags' para velhos, com o único intuito de isolá-los” (GUATTARI; ROLNIK, 1993, p. 43). Não queremos ver o degenerar da vida, que é um avesso da própria vida, a perda da consciência, o alcance de estados diferentes de consciência ou inconsciência que o humano pode vivenciar.

Contudo, rótulos normativos sobre o que é ser velho podem entrar em suspensão quando os idosos apresentam uma resiliência no gesto de irem assistir a um filme, de quererem conversar e comentar sobre o que viram, de pedirem filmes para verem e reverem, de fazerem questão de filmar num lugar tão distante como Lourdes, de ajudarem a montar equipamentos se necessário, como fez Francisco em uma das sessões de cinema (sendo até mesmo censurado pela equipe local desacostumada a vê-lo com iniciativa e destreza em tarefas pouco habituais), demonstrando, portanto, uma autonomia e capacidade de ação, que contradizem discursos institucionais sobre o território existencial dos internos.

Assim, podemos pensar que as experiências de cinema inspiram uma política molecular em meio à política molar do lugar do velho excluído, dependente e frágil. Uma política molecular se insinua nos afrontamentos molares, passa por baixo ou através. São essas linhas de fuga que os idosos apresentam em suas vontades, resiliências, participações, quando oferecem ajuda, quando dão suas opiniões, num encontro de igualdade com os demais atores institucionais. Nesse movimento, os idosos não extraem suas forças do estatuto molar que os doma e petrifica, nem da organização e subjetividade que recebem, mas do devir molecular (DELEUZE, 2012).

"Não se abandona o que se é para se devir outra coisa (imitação, identificação), mas uma outra forma de viver e de sentir assombra ou se envolve na nossa e a 'faz surgir'" (ZOURABICHVILI, 2009, p. 48). Com as experiências de cinema, imaginamos ser possível que idosos extraiam de si outras formas a se viver dentro do asilo. Eles expressam, nesses pequenos gestos desviantes que citamos, desterritorializantes, atitudes que nos causam estranhamento e, também, aos familiares, aos visitantes, à equipe institucional e aos próprios idosos no "assombro" acerca do que podem, sentem e fazem. 
A subjetividade reforçada pelos dispositivos institucionais não é uma verdade sobre os idosos, mas um modo de relação possível construído por cada um dos atores institucionais no cotidiano. Procuramos que o docente em formação, com as experiências de cinema, crie oportunidade para a invenção e emergência de subjetividades singulares, abafadas por uma "produção em série", que insiste em definir e conformar o que os velhos são e podem fazer.

Estranheza, também, porque as experiências de cinema no abrigo invertem a ordem pedagógica convencional da formação de um pedagogo. Como advertimos inicialmente, esta se concentra dentro da escola e na diferença do tempo de vida, experiências de vida, de quem apresenta algo - o professor - a quem chega para viver essa experiência - o aluno. Essa diferença costuma ser marcante no que diz respeito à idade, mas ela também existe como lugar social, no caso da Educação de Jovens e Adultos (EJA), que vai em busca da entrada num universo letrado que o professor já está inserido, e o adulto, mesmo que mais velho, ainda não.
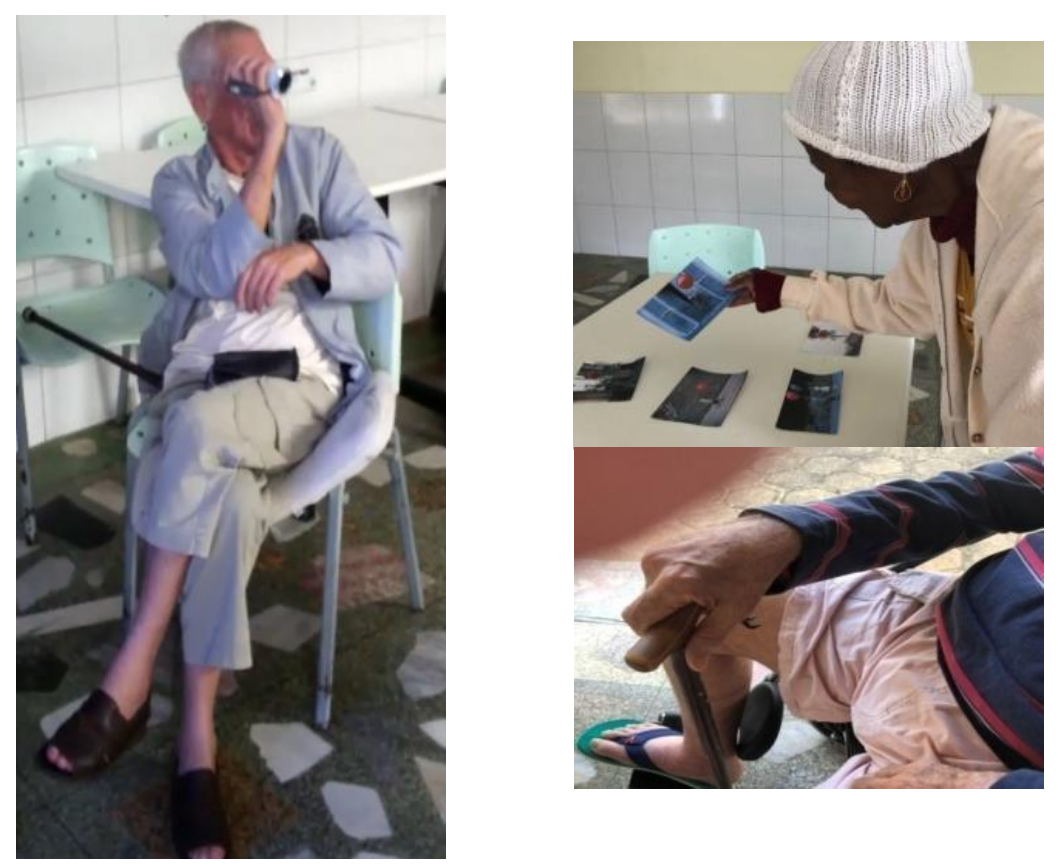

Pode-se abrir uma qualidade de estranheza (e expansão), portanto, pelo docente em formação, que diz respeito ao lugar destinado ao exercício de sua profissão, assim como ao território da aprendizagem, aos modos de aprender, e reflexões sobre a construção social da subjetividade, 
a começar pela velhice. Com potencialidade, imaginamos, de ser expandido aos atores e dispositivos escolares, com quem estamos mais familiarizados e resistentes a reconhecer processos historicamente constitutivos.

\section{O lugar da criação na infância e na velhice}

Para Vigotski (2012), o criar surge como uma necessidade do organismo, impulsionado por uma força inquieta, fruto da inadaptação com o meio. O rompimento de um equilíbrio, que até então o homem mantinha com o ambiente, gera emoções, necessidades, aspirações, desejos que "colocam em movimento o processo da imaginação" (VIGOTSKI, 2012, p. 41). Sob esse prisma, pensamos que os idosos da instituição vivem experiências que são, por si só, da ordem da invenção, já que "experienciam" uma situação de "desequilíbrio" e contradição com o meio, que, até então, lhes era familiar, precisando se integrarem e adaptarem a uma nova realidade. Entender o albergue sob esse ponto de vista nos faz ver, na experiência com os idosos, algumas condições para a criação.

Nos encontros que realizamos com o cinema, entendemos que a atividade criadora possui uma qualidade estética, a qual é anterior aos processos de racionalização e simbolização ainda que estes, também, constituam a criação. Isso significa que, antes da linguagem, que estrutura os modos de conhecer e definir a realidade, nosso acesso ao mundo é mediado pelo sensível. "O sentir é anterior ao pensar e compreende aspectos perceptivos (internos e externos) e aspectos emocionais" (DUARTE JÚNIOR, 1988, p. 16).

Quando exibimos um filme ou convidamos os participantes a realizarem um exercício cinematográfico, estamos em busca dessa qualidade de experiência. Não é necessário que eles entendam o filme completamente, que o apreendam exatamente como ele é, que saibam como manipular uma câmera com destreza e domínio de funções. Uma das potências do cinema como arte é tentar concretizar sentimentos, emoções, sensações, numa forma-imagem, que nem sempre a linguagem consegue anunciar.

Pensamos, a partir de Deligny (2018), na sua relação com as crianças autistas, que nosso objetivo não é trazer os idosos de volta à "nossa linguagem", mas aprender com eles uma nova comunicação e lugar de expressão. Almejamos compor com eles um território, que nos ajude a compreender nosso pensamento antes de se fazer linguagem, já que ele, o próprio pensamento, é, em sua origem, um big bang de nascimento, um sem nexo, confusão, delírio. 
“Todo pensamento, quando começa seu andar, é sempre estúpido, comete múltiplos erros (AGAMBEM, 2011 apud BÁRCENA, 2015, p. 53).

Nesse aspecto, acolhemos as fabulações decorrentes das imagens em movimento projetadas ou as percepções delirantes, que emergem com os exercícios de criação, as quais poderiam ser consideradas irracionais ou sem sentido. Isso porque concordamos com Rancière (2009, p. 58) que "o real precisa ser ficcionado para ser pensado" e a realidade asilar não encerra seu sentido nos dispositivos cotidianos historicamente instituídos.

Por que, na criança, a imaginação é admirada e, no velho, é um delírio desconsiderado? Por que incentivamos a imaginação da criança e, o velho, procuramos "trazer para a realidade"? Observamos que, no abrigo, essa era uma situação recorrente. Havia uma censura ao que os idosos traziam como sendo desprendidos do real e, portanto, indesejados. Com o cinema e as atividades de criação, tentamos abrir espaço para as "des-razões” dos idosos e suas histórias. Foi o que aconteceu com Erondina, que, em meio aos comentários sobre o filme que acabávamos de assistir, A música segundo Tom Jobim, de Nelson Pereira dos Santos (2001), pediu para fugir do asilo. Enquanto os comentários anteriores versavam sobre a relação afetiva que cada um havia tido com o filme, algo lhe despertou em se imaginar em fuga. "Achei lindo. Me emocionei bastante. Muito obrigada por algo tão bonito", comentou Helena, moradora do Albergue. "Adorava ouvir essas músicas. Coisa maravilhosa! Tom Jobim divulgou o Brasil”, disse Francisco, um especial conhecedor da música brasileira e também morador. "Me imaginei fugindo", confessou Erondina, uma senhora, que, por suas limitações motoras, estava sempre aos fundos da sala, recostada numa poltrona sob a qual só podia mexer-se com ajuda.

- Fugir? Você quer fugir para onde? E como vamos fazer?, perguntamos.

- Ué?! Fugir! Sair daqui. Ir para algum lugar. Sem ninguém ver. A gente trabalha. A gente é boba? A gente não é boba. Vamos fugir!

Ao escolhermos dar incentivo ao que foi proposto por Erondina, deslocamos seus "delírios" para o campo da criação e da vida ainda a pulsar, ainda à espera para ser atualizada. Pensamos, com Deleuze (2005), que toda criação/construção é fabulação, e, ao fabular, destruímos modelos de verdade e nos tornamos criadores. Nisso, reside a "potência do falso", amparada na fabulação, criando novos possíveis e novas verdades no mundo.

Que outras verdades e possibilidades acerca dos delírios e irracionalidades do "velho" podem ser criadas com o cinema? Quais velhices são criadas a partir dessas histórias que nos trazem? 
Que território asilar emerge com essas experiências? Acreditamos que a fala dos idosos, considerada desconexa, irracional ou delirante, tem, com o cinema, a possibilidade de ser legitimada e acolhida. Talvez, um "novo" possa emergir dos "velhos" com o cinema; um novo possa emergir da velha forma de cuidar, aprender, conhecer e se relacionar.

\section{Considerações para além do asilo - novos olhares sobre velhos temas}

De que modo, as atividades de cinema com os idosos repercutem nos olhares docentes sobre a instituição escolar e nos modos de ser criança? O que acontece quando o docente em formação retorna à escola depois do asilo? Quais as ressonâncias dessa experiência na relação com as crianças? Como a expectativa acerca do que é a infância e de como está organizada a escola é afetada por essa experiência? Que territórios docentes podem ser tocados, movidos e desterritorializados a partir do que experimentamos?

Procuramos destacar, ao longo do texto, três aspectos, que nos ajudam a pensar essas questões: o contraste rítmico-produtivo da relação professor-criança-velho; o encontro com a velhice como experiência de estranheza e hospitalidade; e a problematização do lugar da imaginação na construção do conhecimento em diferentes fases da vida. Observamos que cada um desses pontos tenciona modos de docência em suas dimensões epistemológica, territorial (relação e ritmo) e metodológica.

Do ponto de vista metodológico, ressaltamos que o modo como conduzimos a pesquisa dialoga com uma proposta relacional, em que não adentramos o espaço para pesquisar os idosos e verificar "impactos" do cinema na saúde, na memória e no bem-estar (ainda que acreditamos que estes ocorram). Nossa perspectiva de trabalho implica, em primeiro lugar, o encontro em uma relação afetiva com aqueles que seriam, em outra perspectiva, "objeto" e "campo" de pesquisa.

Nesse sentido, realizamos uma cartografia da experiência estética com o cinema, acreditando que as ressonâncias de nosso trabalho são indissociáveis de uma certa qualidade de encontro, que procuramos construir com cada um dos atores institucionais. Tal proposta configura-se numa relação com a alteridade, que, pensada em uma dimensão estética, nos desacomoda e nos faz sair do lugar, fazendo com que despontemos professores transformados e transformantes (BEDIN, 2014; DUARTE JÚNIOR, 1988). 
Quanto à dimensão epistemológica, viemos exercitando-a de modo que não se trata de trazer o velho de volta ao mundo da racionalidade, da linguagem e da coerência mnemônica, na tentativa de perpetuar um tipo de vida e conhecimento, que consideramos produtivo e adaptado, mas de aprendermos com eles mais sobre nossos próprios pensamentos primordiais - contraditórios, confusos, "idiotas" - e em como resistir à demanda produtiva da sociedade contemporânea (BÁRCENA, 2015; TÓTORA, 2013). Ao notarmos uma desqualificação da imaginação, podemos nos tornar mais sensíveis à repetição desse padrão nos processos constitutivos da subjetividade, cuja escola é um território fundamental, já que perpassa a relação com o conhecimento, a verdade e o real.

Por último, adentrar um território, cujo ritmo contrasta com aquele comumente experienciado pela docência, pode contribuir para uma postura perceptiva mais sensível aos modos como conduzimos os ritmos escolares, as demandas de produção e as equivalências entre verdade e realidade na construção do conhecimento. Com isso, vislumbramos outras estéticas para o fazer pedagógico, amparados no encontro como instante em que um outro campo intersubjetivo se cria, porque abre em nós, docentes e futuros docentes na relação com os idosos, "estranhos" fazeres, "estranhos" territórios, "estranhos" encontros, ritmos, imagens e histórias.

Ensaiamos com o cinema uma aproximação da experiência dessa etapa avançada da vida não como circunscrita a um tempo cronológico, mas como experiência de pensamento e de uma pedagogia, que pode ser atualizada em todas as idades, a começar por nós, professores, futuros professores e educadores audiovisuais.

\section{Referências}

A música segundo Tom Jobim. Direção: Nelson Pereira dos Santos, 2012. 1 DVD (88min).

BÁRCENA, Fernando. La diferencia (de los idiotas). Revista Pro-Posições, v. 26, n. 1 (76), p. 49-67, jan./abr. 2015.

BEDIN, Luciano. Cartografia: outra forma de pesquisar. Revista Digital do Lav, Santa Maria, v. 7, n. 2, p. 66-77, maio/ago. 2014.

DELEUZE, Gilles; GUATTARI, Félix. A imagem-tempo. Tradução Eloisa de Araujo Ribeiro. São Paulo: Brasiliense, 2005.

DEleuZE, Gilles; GUATTARI, Félix. Mil Platôs: capitalismo e esquizofrenia 2. 2. ed. Tradução Suely Rolnik. São Paulo: Editora 34, 2012, v. 4. 
DELIGNY, Fernand. O Aracniano e outros textos. São Paulo: n-1 edições, 2018.

DUARTE JÚNIOR, João Francisco. Fundamentos estéticos da Educação. 5. ed. Campinas, SP: Papirus, 1988.

FERREIRA, Jacqueline; OMELCZUK, Fernanda. Relatório final de Iniciação Científica. Universidade Federal de São João del-Rei (UFSJ), Pró-Reitoria de Pesquisa. Edital 003/2018.

FRESQUET, Adriana. Cinema e Educação: reflexões e experiência com estudantes de educação básica dentro e "fora" da escola. 1. ed. Rio de Janeiro: Autêntica, 2013.

GALLO, Silvio. René Schérer e a Filosofia da Educação: Aproximações. Anais da 37 Reunião Nacional da ANPEd. Florianópolis. 2015. Disponível em: <http://www.anped.org.br/sites/default/files/trabalho-gt17-3575.pdf>. Acesso em: 7 ago. 2018.

GUATTARI, Félix; ROLNIK, Suely. Micropolítica: cartografias do desejo. Petrópolis: Vozes, 1993.

KASTRUP, Virgínia. Pistas do método da cartografia - a experiência da pesquisa e o plano comum. Porto Alegre: Sulina, 2014, v. 2.

MASSCHELEIN, Jan; SIMONS, Maarten. Em defesa da escola: uma questão pública. Belo Horizonte: Autêntica, 2014.

ORLANDI, Luiz. Um gosto pelos encontros. 2014. Disponível em: $<$ https://territoriosdefilosofia.wordpress.com/2014/12/29/um-gosto-pelos-encontros-luizorlandi/>. Acesso em: 19 ago. 2018.

RANCIÈRE, Jacques. A partilha do Sensível: estética e política. São Paulo: EXO experimental, Editora 34, 2009.

RANCIÈRE, Jacques. O Mestre ignorante: cinco lições sobre a emancipação intelectual. Belo Horizonte: Autêntica, 2011.

TÓTORA, Silvana. Genealogia da velhice. Ecopolítica, [S.1.], n. 6, maio/ago. 2013. Disponível em: <https://revistas.pucsp.br/index.php/ecopolitica/article/view/16754>. Acesso em: 7 ago. 2018.

VIGOTSKI, Lev. Imaginación y creación en la edad infantil. Lanús Oeste: Nuestra América, 2012.

ZOURABICHVILI, François. O vocabulário de Deleuze. Rio de Janeiro: Relume Dumará; Sinergia; Ediouro, 2009. 